\title{
Clinical Research of Soft Tissue Balance Technique in the Treatment of Knee Osteoarthritis
}

\author{
Cheng Tingxiu*, Cheng Guangyao and Liu Shuqiang \\ Department of Rehabilitation, Dongning City People's Hospital, China
}

Submission: July 04, 2018; Published: October 17, 2018

*Corresponding author: Cheng Tingxiu, Department of Rehabilitation, Dongning City People's Hospital, Heilongjiang province, 157299, China, Email: chengtingxiu@163.com

\section{Abstract}

Objective: Clinical efficacy of soft tissue balance technique in the treatment of knee osteoarthritis.

Methods: 120 cases of knee osteoarthritis were randomly divided into two groups: treatment group and control group, Each group of 60 cases. Treatment group was treated with soft tissue balance technology, the control group was treated with traditional massage therapy, Treatment 4 week. Compare the two groups before and after treatment HSS score and VAS score and evaluate the curative effect.

Results: The cure rate and total effective rate of the treatment group were significantly better than that of the control group (Ridit analysis, $\mathrm{u}=5.0818, \mathrm{P}<0.01$, The difference between the two groups was statistically significant); The function and pain of the treatment group were better than that of the control group(HSS score compared with the control group: $t=22.287, \mathrm{P}<0.01$; VAS score compared with the control group: $\mathrm{t}=6.242, \mathrm{P}<0.01)$.

Conclusion: Soft tissue balance technique is simple, practical and effective in the treatment of knee osteoarthritis, and is suitable for clinical application.

Keywords: Soft tissue balance; Knee osteoarthritis; Clinical research

\section{Introduction}

Knee osteoarthritis (KOA) is a chronic osteoarthritis disease. It is a common and frequent disease in orthopedics clinic. The quality of life of patients is seriously affected. In recent years, soft tissue balance technology has been widely used in knee arthroplasty [1,2]. In recent years, the author has used soft tissue balance technology to treat knee osteoarthritis conservatively and achieved remarkable curative effect.

\section{Clinical data}

From January 2014 to January 2016, 120 patients with knee osteoarthritis were admitted to the department of rehabilitation medicine of dongning people's hospital. The patients were randomly divided into treatment group and control group. There was no statistically significant difference in gender, age, course of disease, HSS score and VAS score before and after treatment $(\mathrm{P}>0.05)$. All patients were diagnosed as knee osteoarthritis according to the diagnostic criteria of osteoarthritis guidelines (2007 edition) [3]

\section{Treatment method}

The control group: The traditional massage method is fully referred to the massage prescription of knee osteoarthritis in the "diagram of traditional Chinese medicine orthopedics and traumatology treatment methods" (second edition) [4]. Each knee manipulation treatment time is 30 minutes.
Key points of operation: the patient is recumbent, slightly kneeling, and the doctor holds up the knee with one hand and points the blood hole with the other hand with the thumb, so as to regulate qi and activate blood circulation. Some points of knee eye: before the same position, the doctor points the patient's bilateral knee hole with both hands. Patients lie on their knees and bend their knees. The physician crosses his hands and thumbs and presses the inferior iliac ligament. Ongoing kneading: in practice, patella is kneaded to promote airflow throughout the knee and improve joint activity and function. The patient extends the knee, presses the lower line of the patella with both hands and thumbs, pushes up and kneads it, then presses down the upper margin of the patella and pushes down several times. Patellar articulation: the physician fastens the patella with one hand, fastens the patella up with force, and repeatedly withdraws the patella along the side line of the patella. The semi-squat position of the patient, the semisquat position of the doctor, one hand on the ankle, anti-clockwise direction or clockwise direction repeatedly shake several times, can remove the joint interlock, relieve pain.

The treatment group: According to the soft tissue balancing techniques [5] treatment plan design, the first application methods such as push, take, press, kneading, relax muscles around the knee joint, the patient decubitus position according to relax change position for patients with stomach, lie on your 


\section{Journal of Yoga and Physiotherapy}

back, and side; Specific treatment include quadriceps, hamstrings, glutes, kuo tensor fascia, the iliotibial band and adduction muscle group, calf triceps muscle, such as the tibialis anterior muscle and massage every part 2 min, treatment time of 20 minutes; Then, the quadriceps and hamstring muscles were subjected to multipoint equi-length stretching and contraction training [6,7], and the treatment lasted 10 minutes. Once a day, 6 days for a course of treatment; The next course of treatment is conducted at intervals of one day; The main clinical symptoms, signs and life ability of the patients were observed after 4 courses of treatment.

\section{Results}

\section{Curative effect of standard}

Refer to the relevant standards in the guiding principles for clinical research of traditional Chinese medicine new drugs [8]. Cure: the clinical symptom disappeared, the joint function activity returns to normal. Obvious effect: clinical symptoms disappear basically or main symptom is eliminated basically, joint activity recovers basically, can work normally and labor. Effective: the main symptoms were basically eliminated, and the function of Table 1: Comparison of clinical efficacy between the two groups [n (\%)]. joint activity was obviously recovered. Invalid: no improvement in symptoms and joint function.

The Hospital for Special Surgery (HSS) knee joint score standard [9] was adopted to assess. The knee joint function of the affected side before and after treatment. Visual analogue Scale (VAS) was used to assess the degree of pain before and after treatment.

\section{Statistical method}

SPSS13.0 was used for statistical treatment, $t$ test was used for measurement data, and Ridit analysis was used for grade data, $\mathrm{P}<0.05$ was considered statistically significant.

\section{The treatment results}

Comparison of clinical efficacy between the two groups (see Table 1): As can be seen from Table 1, the total effective rate of the treatment group was $100 \%$, and that of the control group was $75 \%$. The comparison difference between the two groups was statistically significant $(\mathrm{P}<0.01)$.

\begin{tabular}{|c|c|c|c|c|c|c|}
\hline Group & $\mathbf{n}$ & The More Clinical Cure & Significant Effect & $\begin{array}{c}\text { Clinical } \\
\text { Effective }\end{array}$ & Clinical Invalid & $\begin{array}{c}\text { Total Effective Rate } \\
/ \%\end{array}$ \\
\hline The treatment group & 60 & $41(68.33)$ & $18(30.00)$ & $1(1.67)$ & $0(0.00)$ & 100 \\
\hline The control group & 60 & $20(33.33)$ & $11(18.33)$ & $14(23.33)$ & $15(25.00)$ & 75 \\
\hline
\end{tabular}

Explain: Compared with the control group, according to Ridit analysis, $\mathrm{u}=5.0818, \mathrm{P}<0.01$.

Comparison of HSS scores and VAS scores between the two groups before and after treatment (see Table 2): It can be seen from Table 2 that the HSS scores and VAS scores of the two groups before treatment were not statistically significant $(\mathrm{P}>0.05)$. HSS scores and VAS scores of the two groups after treatment were compared, and the difference was statistically significant $(\mathrm{P}<$ 0.01).

Table 2: Comparison of HSS score and VAS score between the two groups before and after treatment (score).

\begin{tabular}{|c|c|c|c|c|}
\hline Group & $\mathbf{n}$ & Time & HSS Score & VAS Score \\
\hline \multirow{2}{*}{ The treatment group } & \multirow{2}{*}{60} & Before the treatment & $50.01 \pm 9.65$ & $8.41 \pm 1.58$ \\
\cline { 3 - 5 } & & After treatment & $90.18 \pm 7.59^{11}$ & $1.98 \pm 0.65^{2)}$ \\
\hline \multirow{2}{*}{ The control group } & \multirow{2}{*}{60} & Before the treatment & $49.98 \pm 9.78$ & $8.46 \pm 1.49$ \\
\cline { 3 - 5 } & & After treatment & $60.55 \pm 6.96$ & $3.79 \pm 2.13$ \\
\hline
\end{tabular}

Explain: Comparison of HSS score and control group $t=22.287$, 1) $P<0.01$; VAS score was compared with control group $t=6.242,2) P<0.01$.

\section{Discussion}

Knee osteoarthritis (knee osteoarthritis, KOA) is a common clinical chronic joint disease, according to the world health organization (WHO), 4 of osteoarthritis in female prevalence, it is in men the eighth, the crowd over 40 knee osteoarthritis total prevalence was $28.7 \%$ [10]. China has entered an aging society. By the end of 2009, the number of elderly people aged 65 or above in China exceeded 113 million, and the number increased year by year [11]. In China, $50 \%$ of people over 60 years old have osteoarthritis on the $\mathrm{X}$ line, and $35 \%$ to $50 \%$ have clinical symptoms [12]. In recent years, knee osteoarthritis has attracted high attention from the society, and the treatment of knee osteoarthritis has also become a concern of the medical community [13].
Due to degeneration and changes in the negative gravity line, knee osteoarthritis leads to dysfunction of the locking mechanism of the knee joint, which damages the stability of the knee joint [14]. The stability of the joint depends on the surrounding soft tissue and its balance $[15,16]$. The articular surface and surrounding muscles and ligaments ensure the range of physiological activities of the knee joint, and the surrounding muscles act as power devices to maintain the balance of lower limb movements. Normal joint activity depends on the results of the coordination and antagonism between the muscles around the joint. The main factor to maintain the stability of the joint is the balance of forces between the muscles [17].

The soft tissue balance technique is mainly used to loosen the soft tissue around the joint contracture. The adjustment of 


\section{Journal of Yoga and Physiotherapy}

mechanical balance of soft tissue can effectively adjust the stress state of knee joint, restore the function of knee joint and improve the stability of knee joint. Always soft tissue balancing technique is applied to knee replacement, the author introduces the technology of conservative treatment knee osteoarthritis clinical study, the method first relax all muscles around the knee joint, the shortening and stretching stiff muscles, and then the quadriceps and hamstring multipoint isometric isotonic contraction training, more training, respectively, the quadriceps muscle and training four muscles, make the quadriceps and hamstring strength $(\mathrm{Q} / \mathrm{H})$ rebalancing, recovery of soft tissue balance; So it's therapeutic. Study according to the technical design of soft tissue balance treatment of knee osteoarthritis treatment cure rate and total effective rate is better than traditional massage group (via Ridit analysis, $\mathrm{u}=5.0818, \mathrm{P}<0.01$ is similar between the two groups have statistical significance); According to the design treatment of soft tissue balance technology treatment of knee joint function in patients with knee osteoarthritis and improve the degree of pain is better than traditional control group $(\mathrm{t}=22.287$, compared with controls HSS score $(\mathrm{P}<0.01$; VAS score was compared with control group $\mathrm{t}=6.242, \mathrm{P}<0.01$ ).

To sum up, soft tissue balance technology applies not only to knee arthroplasty [18-20], in a conservative plays an important role in treatment of knee osteoarthritis, through soft tissue balance is good and stable to the line, to restore the knee to the painless, stability, activity function good condition; This method is simple, practical and effective, suitable for clinical promotion.

\section{References}

1. He X, Hong CAI, Zhang K (2016) Progress of soft tissue balance technology in total knee arthroplasty. China Medical Journal 13(9): 80-83.

2. Jia H, Liu Z, Li lei J (2015) Application of soft tissue balance technology in knee arthroplasty of uyghurs. Chinese Tissue Engineering Research 19(26): 4144-4147.

3. Chinese Medical Association (2007) Guidelines for the diagnosis and treatment of osteoarthritis. Chinese Journal of Orthopaedics 27(10): 793-795.

4. (2008) Shanghai science and technology press, Shanghai, China, 12: 192-193.

5. Liu F, He D, Xingli L, Zhao L (2005) Soft tissue balance in total knee replacement. Journal of Clinical Surgery 13(8): 524-525.

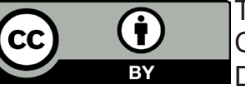

This work is licensed under Creative

Commons Attribution 4.0 License

DOI: 10.19080/JYP.2018.06.555691
6. Lu Y, haizheng L (2017) Director shi yusheng treated knee osteoarthritis by pushing knee eyes combined with acupuncture. Jilin Traditional Chinese Medicine 37(1): 32-35.

7. Kangyan L, Hailan H, Yong C (2016) Relationship between quadriceps muscle strength and osteoporosis and knee osteoarthritis. Chinese Journal of Joint Surgery 10(3): 271-276.

8. Zheng X (2002) Guiding principles for clinical research of traditional Chinese medicine new drugs. China Medical Science and Technology Press, Beijing, China, pp: 349-353.

9. Yunpeng L, liu Y (2002) Diagnostic classification and functional evaluation criteria of bone and joint injuries and diseases.: Tsinghua University Press, Beijing, China, pp: 232-233.

10. Ninghua L, Qingyun X, Zhang Y (2008) Epidemiological analysis of X-ray knee osteoarthritis among middle-aged and elderly people in six Chinese cities. Journal of Practical Medicine 24(16): 2887-2888.

11. Huang Y, Xiaoguang T (2012) Analysis of China's population aging status. Chinese Journal of Gerontology 32(21): L4853-L4855.

12. (2012) People's military medical publishing house, Beijing, China, pp 1339-1345.

13. Huaping P, Feng H, Yuelong C (2011) Advances in the treatment of knee osteoarthritis by hand therapy combined with exercise therapy. Chinese Journal of Traditional Chinese Medicine 26(12): 2934-2938.

14.Jian W (2007) Development of soft tissue balance measurement techniques in knee replacement. Journal of Biomedical Engineering 24(4): 937-940.

15. Changchun Y, Wang Z, Shang Y (2007) Soft tissue balance of total knee arthroplasty with varicular deformity of the knee. Chinese Journal of Repair and Reconstruction Surgery 21(10): 1062-1067.

16. Junyong H, Dongliang X, Shiming Y (2006) Soft tissue balance of total knee arthroplasty for severe knee osteoarthritis. Guangdong Medicine 27(2): 151-152.

17. Dang H, Wang P, Chen W (2006) The significance of soft tissue balance in total hip replacement. Chinese Journal of Bone and Joint Injury 21(5): 344-346.

18. Chen Y, Zhang Z (2016) Advances in surgical techniques of total knee arthroplasty for varus knee. Chinese Journal of Clinical Physicians 10(17): 2675-2679.

19. Zhang Y (2016) Computer-aided total knee arthroplasty localization and soft tissue balance. Chinese Tissue Engineering Study 20(9): 13021308.

20. Li H, Ge W, Shengxiang W (2017) Analysis on the effects and advantages of knee arthroplasty in the treatment of knee osteoarthritis. Chinese Medical Journal 19(1): 19-20.

Your next submission with Juniper Publishers
will reach you the below assets
- Quality Editorial service
- Swift Peer Review
- Reprints availability
- E-prints Service
- Manuscript Podcast for convenient understanding
- Global attainment for your research
- Manuscript accessibility in different formats
( Pdf, E-pub, Full Text, Audio)
- Unceasing customer service
Track the below URL for one-step submission
https://juniperpublishers.com/online-submission.php

